\title{
Experimental Nonlinear Modeling of a Rotating Machine with an Oil Film Bearing
}

\author{
Chiou-Fong Chung \\ Department of Mechanical Engineering, National Central University, Chung-Li, Taiwan 32054. \\ Pi-Cheng Tung \\ Department of Mechanical Engineering, National Central University, Chung-Li, Taiwan 32054., t331166@ncu.edu.tw \\ Chiang-Nan Chang \\ Department of Mechanical Engineering, National Central University, Chung-Li, Taiwan 32054.
}

Follow this and additional works at: https://jmstt.ntou.edu.tw/journal

Part of the Mechanical Engineering Commons

\section{Recommended Citation}

Chung, Chiou-Fong; Tung, Pi-Cheng; and Chang, Chiang-Nan (2002) "Experimental Nonlinear Modeling of a Rotating Machine with an Oil Film Bearing," Journal of Marine Science and Technology. Vol. 10: Iss. 2, Article 6.

DOI: $10.51400 / 2709-6998.2309$

Available at: https://jmstt.ntou.edu.tw/journal/vol10/iss2/6

This Research Article is brought to you for free and open access by Journal of Marine Science and Technology. It has been accepted for inclusion in Journal of Marine Science and Technology by an authorized editor of Journal of Marine Science and Technology. 


\section{Experimental Nonlinear Modeling of a Rotating Machine with an Oil Film Bearing}

\section{Acknowledgements}

The authors would like to thank Jo-Wan Lin for this invaluable assistance and cooperation. The authors would also like to thank the support by National Science Council, Republic of China, through supporting this research under Grant No. NSC 88-TPC-E-008-001. 


\title{
EXPERIMENTAL NONLINEAR MODELING OF A ROTATING MACHINE WITH AN OIL FILM BEARING
}

\author{
Chiou-Fong Chung, Pi-Cheng Tung, and Chiang-Nan Chang
}

Key words: identification, oil whirl, unbalanced mass.

\begin{abstract}
In this study the system identification method is applied to obtain a nonlinear equation for an oil film rotating system. The centrifugal force induced by an unbalanced mass is used as the input signal for identification, and the phase between the input signal and the measured output vibration amplitude is calculated to perform the identification. Stability analysis and system performance are evaluated by using the root locus and the Floquet-Liapunov theorem. Based on the model, the oil whirl of the journal bearing can be predicted. A comparison between the simulation results and some experimented data shows the feasibility of the proposed approach.
\end{abstract}

\section{INTRODUCTION}

The fluid model of an oil-film bearing system has been studied by several workers [1-3]. Muszynska et al. [4,5] established the fluid force system model in 1986. In practical applications, these mathematical models can not be used to predict the occurrence of the oil whirl because they are all derived theoretically, based on certain simple assumptions, and do not identify the system with the experiment results. Thus mathematical models are only used for theoretical analysis and simulation, not for on line diagnosis. Several different time-domain and frequency-domain techniques [6-11] have been developed for identifying the oil-film coefficients of the bearing, but these studies only identified the linear parts of the system or a system that was linearized. They did not identify the nonlinear parts of the system. Some scholars have identified a nonlinear oil-film bearing system [12-15], using the traditional excitation methods, such as impacts or sweep sines to perturb the experimental oil film bearing system,

Paper Submitted 04/03/02, Accepted 07/17/02. Author for Correspondence: Pi-Cheng Tung.

*Department of Mechanical Engineering, National Central University, Chung-Li, Taiwan 32054.E-mail: t331166@ncu.edu.tw for the purposes of identification. However, these methods are not suitable for use in practical applications, because a rotating machine does not permit an external force to disturb or change the system once it is in motion.

Zhao et al.[16] pointed out that the fluid force induced by the oil in the bearing is related to the operating speed. Thus, we deal with the model in the frequency domain for such reasons as less susceptibility to noise, more convenience of identification, and easier correction of rotating machinery malfunctions. For exhaustive observation of the signals system is input and output, we transform the time domain data to frequency domain data, by using the Discrete Fourier Transform (DFT). The system identification method is applied based on the principle of harmonic balance [1719]. In order to perform system identification, the input signal and the output signal should be obtained simultaneously. An unbalanced mass force is used as the system excitation force. We developed a method to calculate the phase between the input unbalanced force and the measured vibration amplitude. After obtaining the phase, we can establish the identification method, obtaining a mathematical model by the principle of harmonic balance. By performing stability analysis [20], we can predict the speed at which an oil whirl occurs.

\section{ALGORITHM OF IDENTIFICATION}

The equation for a single-degree-of-freedom can be written as

$$
m \ddot{x}+c \dot{x}+k x+\tilde{N}=f
$$

where $m, c$, and $k$ denote the mass, the damping and the stiffness in the linear part of the system. The parameter $\tilde{N}$, represents the nonlinear part of the system, and it is a function of $x . f$ is the external force in equation (1). The algorithm of identification is described as follows [21]: 


\section{Step 1:}

Assume that the nonlinear term $\tilde{N}$ is approximated by a polynomial of $x$ :

$$
\tilde{N}=\alpha x^{2}+\beta x^{2}+\ldots
$$

where $\alpha, \beta \ldots$ are unknown coefficients. When this assumption is made, the problem of identification is reduced to the determination of the parameters $m, c$, and $k$ in equation (1), and the unknown coefficient $\alpha, \beta \ldots$ in equation (2).

\section{Step 2:}

When a periodic external force $f$, with a period $T=$ $\frac{2 \pi}{\omega}$, is applied to the system, the steady-state responses $x$, with the same period as the external force, are induced. Then, both the external force $f$ and the steady-state response $x$ are recorded within the time interval of one period.

\section{Step 3:}

Transfer the external force $f$ and the steady-state response $x$ into the Fourier series [8].

\section{Step 4:}

Express the input force term and each term in the equation of motion including the nonlinear terms in Fourier series. Then, equation (1) and equation (2) can be expressed as a matrix in the form of :

$$
[A]\{X\}=\{F\},
$$

where:

$$
\begin{aligned}
& {[A]=\left[\begin{array}{cccccc}
0 & 0 & x_{O R} & \left(x^{2}\right)_{O R} & \left(x^{3}\right)_{O R} & \cdots \\
-\omega^{2} x_{1 R} & \omega x_{1 I} & x_{1 R} & \left(x^{2}\right)_{1 R} & \left(x^{3}\right)_{1 R} & \cdots \\
-\omega^{2} x_{1 I} & -\omega x_{1 R} & x_{1 I} & \left(x^{2}\right)_{1 I} & \left(x^{3}\right)_{1 I} & \cdots \\
-4 \omega^{2} x_{2 R} & 2 \omega x_{2 I} & x_{2 R} & \left(x^{2}\right)_{2 R} & \left(x^{3}\right)_{2 R} & \cdots \\
-4 \omega^{2} x_{2 I} & -2 \omega x_{2 R} & x_{2 I} & \left(x^{2}\right)_{2 I} & \left(x^{3}\right)_{3 I} & \cdots \\
\vdots & \vdots & \vdots & \vdots & \vdots &
\end{array}\right]} \\
& \{X\}=\left[\begin{array}{llllll}
m & c & k & \alpha & \beta & \ldots
\end{array}\right]^{T} \\
& \{F\}=\left[\begin{array}{llllll}
f_{0 R} & f_{1 R} & f_{1 I} & f_{2 R} & f_{2 I} & \ldots
\end{array}\right]^{T}
\end{aligned}
$$

If the various values of $\omega$ are properly calculated, we can transfer equation (1) correctly into equation (3). We know that $\{x\}$ is an unknown vector, solved by the least-square estimator (LSE)[19]. The result of the LSE is then:

$$
\{\hat{X}\}=\left([A]^{T}[A]\right)^{-1}[A]^{T}\{F\},
$$

From equation (5), we get the parameters $m, c, k$, $\alpha, \beta \ldots$ for the system. If necessary, the weighting matrix can be used to improve the accuracy. When the weighting matrix $[W]$ is used, equation (5) becomes:

$$
\{\hat{X}\}=\left([A]^{T}[W][A]\right)^{-1}[A]^{T}[W]\{F\},
$$

The Apparatus and the Experiment Figure 1 and Figure 2 show a schematic diagram and a photo of the oil film rotating system. A proximitor assembly is used as the vibration probe along the horizontal direction( $\mathrm{x}$ axis). The keyphasor probe is located at the shaft notch also in a horizontal direction. A rigid bearing near the motor side, and a lubricated cylindrical bearing on the other side support this rotor system. We put the unbalanced disk of the rotating shaft near the oil film bearing to reduce the degrees of freedom. Thus, the equation of motion in the rotor system can be simplified as a onedegree-of-freedom system. To establish a mathematical model of an oil film bearing system that analyzes the

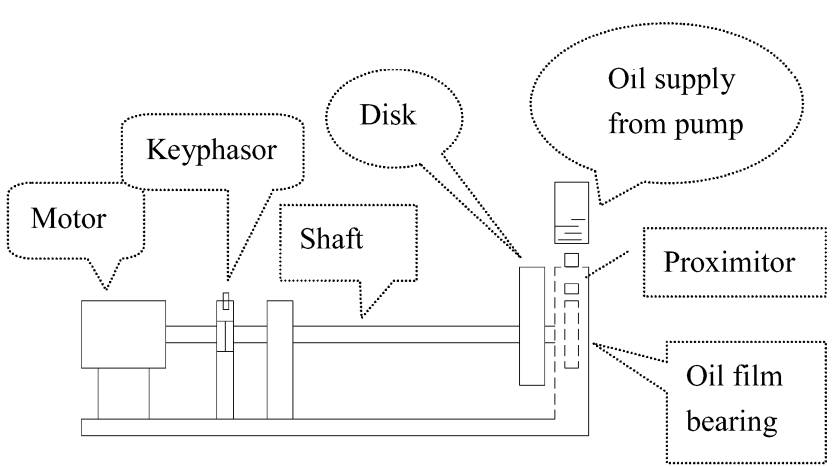

Fig. 1. Structure of the experimental oil-film bearing.

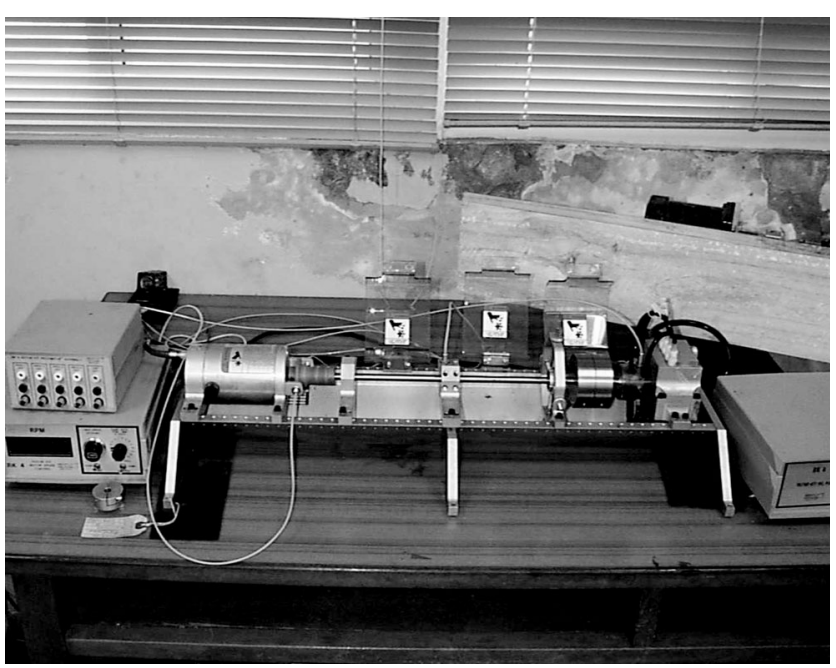

Fig. 2. Photograph of the experimental equipment. 
Table 1. Experimental data

\begin{tabular}{cccccccc}
\hline \multicolumn{2}{c}{ Channel Name: Channel 1 } & \multicolumn{3}{c}{ Machine Name: Rotor Kit } & \multicolumn{3}{c}{ Amplitude Units: $\mu \mathrm{m}$} \\
Sample & Date & Time & Speed & Direct & Gap & Amplitude & Phase \\
\hline 71 & 24APR2001 & $19: 10: 05$ & 1820 & 45.46 & -8.91 & 42.42 & 151 \\
72 & 24APR2001 & $19: 10: 05$ & 1830 & 47.50 & -8.92 & 43.18 & 151 \\
73 & 24APR2001 & $19: 10: 06$ & 1840 & 45.72 & -8.91 & 42.67 & 152 \\
74 & 24APR2001 & $19: 10: 06$ & 1850 & 45.47 & -8.92 & 42.93 & 153 \\
75 & 24APR2001 & $19: 10: 06$ & 1860 & 45.72 & -8.92 & 42.93 & 153 \\
76 & 24APR2001 & $19: 10: 07$ & 1870 & 46.23 & -8.92 & 42.93 & 153 \\
77 & 24APR2001 & $19: 10: 07$ & 1880 & 46.48 & -8.92 & 42.67 & 154 \\
78 & 24APR2001 & $19: 10: 07$ & 1890 & 50.55 & -8.92 & 42.67 & 154 \\
79 & 24APR2001 & $19: 10: 08$ & 1900 & 58.42 & -8.92 & 42.67 & 154 \\
80 & 24APR2001 & $19: 10: 08$ & 1907 & 59.94 & -8.92 & 42.93 & 153 \\
\hline
\end{tabular}

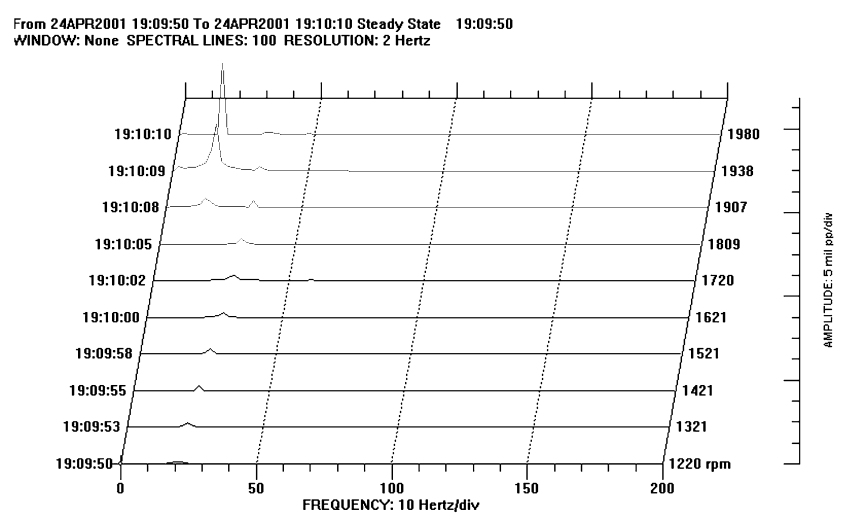

Fig. 3. Waterfall diagram of the oil film bearing system.

vibrational phenomena in the oil film bearing, is the main object of this study. It is helpful to observe the oil whirl phenomenon by running an experimental rotor kit set-up before the mathematical model is found. When the oil film bearing system, rotating in its fluid lubricated cylindrical bearings, has a lightly loaded, slightly unbalanced symmetric rotor, the dynamic phenomena is quite apparent. The vibration data for our experimental oil film bearing system are shown as Figure 3. The inertia forces of the unbalanced rotor mass may cause the vibrations at low operating speeds. At low rotational speeds, these vibrations are stable, and we can neglect the impulse perturbation of the rotor that causes a short term transient vibrational process. When the rotation speed increases, the synchronous vibration is not the only system motion. Along with first harmonic vibrations, an oil whirl appears, cause by the rotor's lateral forward subharmonic vibration around the bearing center at a frequency close to half the rotation speed (usually smaller than half). The amplitudes of the oil whirl are usually much higher than those of the synchro- nous vibrations, because the oil whirl occurs due the nonlinear fluid forces. At $1900 \mathrm{rpm}$ shown in Table 1, the vibration of the system becomes unstable and the bearings fluid force becomes the main factor which influences the amplitude.

According to the dynamic phenomena described above, there are two causes of system vibration. One is the synchronous vibration caused by an unbalanced force, and the other is self-excitation caused by the nonlinear fluid force. When the vibration frequency grows, the nonlinear factors influence the system more. In order to perform identification, we need an external force to excite the oil film rotational system. Without using additional excitation equipment, the unbalanced mass already existing in the system may be used as the excitation force. Suppose that the unbalanced mass is $m$, the distance between the unbalanced mass and the center of the disk is $r$, the rotational speed of the system is $\omega$, and the phase angle between the input and the output in $x$-axis is $\theta_{x}$. The external force caused by an unbalanced mass is $F_{\text {unbalance }}=m r \omega^{2}$.

Since the systems input force can be estimated from the unbalanced mass, only the systems output can be measured during its operation. However, for performing system identification the systems input and output should be recorded simultaneously. To find the phase angle is the key to performing identification using an unbalanced mass as the excitation force. The system phase angle is the phase lag between the systems input and output. The calculation of the system phase angle is shown as Figure 4 and is described as follows.

If the speed of rotation is far below the first critical speed of the system, the phase angle is zero. In this case the heavy spot (the unbalanced mass) can be located by observing the angle $\theta_{1}$ (as indicated in Figure 4a) from the keyphasor dot on the time response to the next positive peak on the time response. Thus, if the machine 
is stopped and the notch on the shaft lined up with the keyphasor probe, the heavy spot will be located at the observed angle $\theta$ as indicated in Figure 4(b), away from the vibration probe. For the case that the speed of rotation is far below the first critical, then $\theta_{1}$ is equal to $\theta$ and the phase angle $\theta_{x}$ between input response and output response is zero. Since the location of the heavy spot in the oil-film rotating system is already known, the phase angle $\theta_{x}$ for any rotational speed can be obtained by calculating the difference between the angle $\theta$ of the heavy spot and the vibration probe after the keyphasor probe is lined up with the notch on the shaft, and the angle $\theta_{2}$ of the keyphasor dot and the next peak on the time response as indicated in Figure 4(c). The calculation of the phase $\theta_{x}$ is expressed as $\theta_{x}=\theta_{2}-\theta_{1}$. After obtaining the phase angle, the system input corresponds with the output and we can perform identification experimentally.

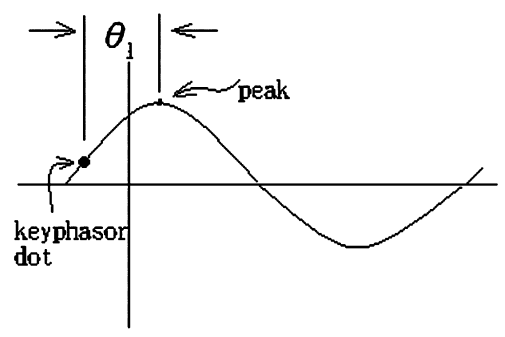

(a)

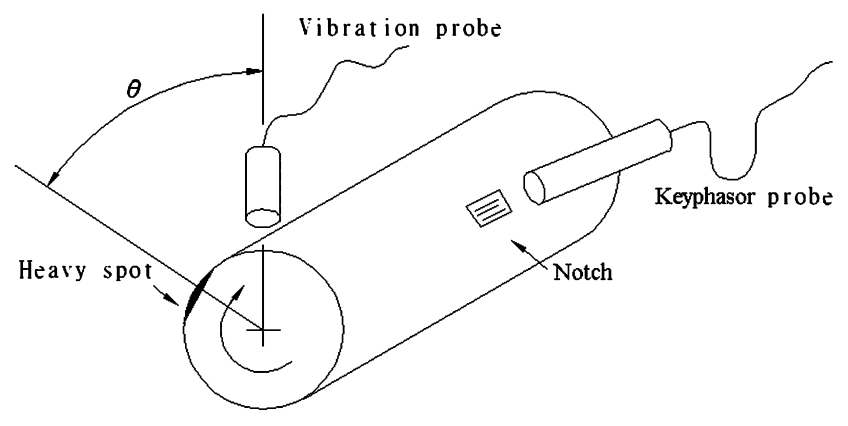

(b)

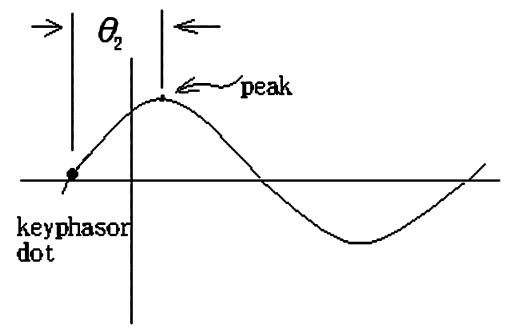

(c)

Fig. 4. The relationship of system phase angle.

\section{EXPERIMENT WITH OIL FILM BEARINGS AND IDENTIFICATION RESULTS}

In this experiment, we adopt a linear approach to identifing the oil-film rotating system. The linearized simplified system model is assumed to be:

$$
m_{x} \ddot{x}+c_{x} \dot{x}+k_{x} x=m^{*} r^{*} \omega^{2 *} \cos (\omega t)
$$

It should be noted that the parameters of the inertial, damping, and stiffness terms of the oil-film system are a function of the rotational speed. Thus, the parameters of the linearized system are dependent on the rotational speed. The parameters of the linearized system vary as the rotational speed varies. By performing stability analysis on the linearized system, we can predict at which rotational speeds the linearized system will become unstable and when an oil whirl will occur. We identify the parameters of the one-dimensional linearized oil-film bearing system in the $x$-axis. Based on the identification method used in section 2 , the system is identified from $1400 \mathrm{rpm}$ to $1880 \mathrm{rpm}$. The results and the eigenvalues for the linearized system are shown in Table 2. It should be noted that since the equivalent mass, damping, and stiffness of the system are a function of the rotational frequency, the parameter values of $m, c, k$ will be varied with this frequency.

In Table 2, we find that the damping coefficient becomes small when the frequency is increased, and that the eigenvalues are close to the image axis. Figures 5 and 6 show the real time responses at $1860 \mathrm{rpm}$ and $1880 \mathrm{rpm}$. Figure 7 shows the root locus of the linearized oil film bearing system. This means that when the frequency is growing and the damping coefficient is getting smaller, the system becomes unstable. In this experiment, the system becomes unstable at the frequency of $1900 \mathrm{rpm}$. In table 2, we see that the eigenvalues change very fast. Although at $1800 \mathrm{rpm}$ they are not very close to the image axis, we can expect that the eigenvalues will cross the image axis if the frequency is increased slightly.

The experimental results show that the linear model can only predict until the speed where the system become unstable. Theoretically it can not show what happens after a system becomes unstable. However, the experimental results show that the oil whirl occurs after the rotational speed that the identified linear system becomes unstable. In order to characterize the systems behavior due to nonlinear effects we adopt a nonlinear approach to the identification of oil film rotating system. We assume that the nonlinear term is $N=\alpha x^{2}+\beta x^{3}+\ldots$ Then the system model is

$$
m_{x} \ddot{x}+c_{x} \dot{x}+k_{x} x+\beta x^{3}=m^{*} r^{*} \omega^{2 *} \cos (\omega t),
$$


Table 2. ID Results and eigenvalues for a linearized system on the $x$-axis

\begin{tabular}{ccccc}
\hline Frequency $(\mathrm{rpm})$ & $m_{x}(\mathrm{~kg})$ & $c_{x}(\mathrm{Kg} / \mathrm{sec})$ & $k_{x}\left(\mathrm{Kg} / \mathrm{sec}^{2}\right)$ & Eigenvalues \\
\hline 1400 & 0.0968 & 98.854 & 15489.837 & $-827.714,-193.285$ \\
1500 & 0.0726 & 74.887 & 13146.133 & $-807.358,-224.323$ \\
1600 & 0.0742 & 77.936 & 14976.191 & $-797.529,-253.158$ \\
1700 & 0.0733 & 64.247 & 17117.222 & $-438.31 \pm 203.57 \mathrm{j}$ \\
1800 & 0.0661 & 48.376 & 16680.106 & $-365.91 \pm 344.16 \mathrm{j}$ \\
1820 & 0.0628 & 45.387 & 16515.354 & $-361.20 \pm 363.87 \mathrm{j}$ \\
1840 & 0.0593 & 37.445 & 16413.779 & $-315.67 \pm 420.83 \mathrm{j}$ \\
1860 & 0.0615 & 31.773 & 17481.478 & $-258.23 \pm 466.34 \mathrm{j}$ \\
1880 & 0.0665 & 21.281 & 18420.124 & $-160.00 \pm 501.38 \mathrm{j}$ \\
\hline
\end{tabular}

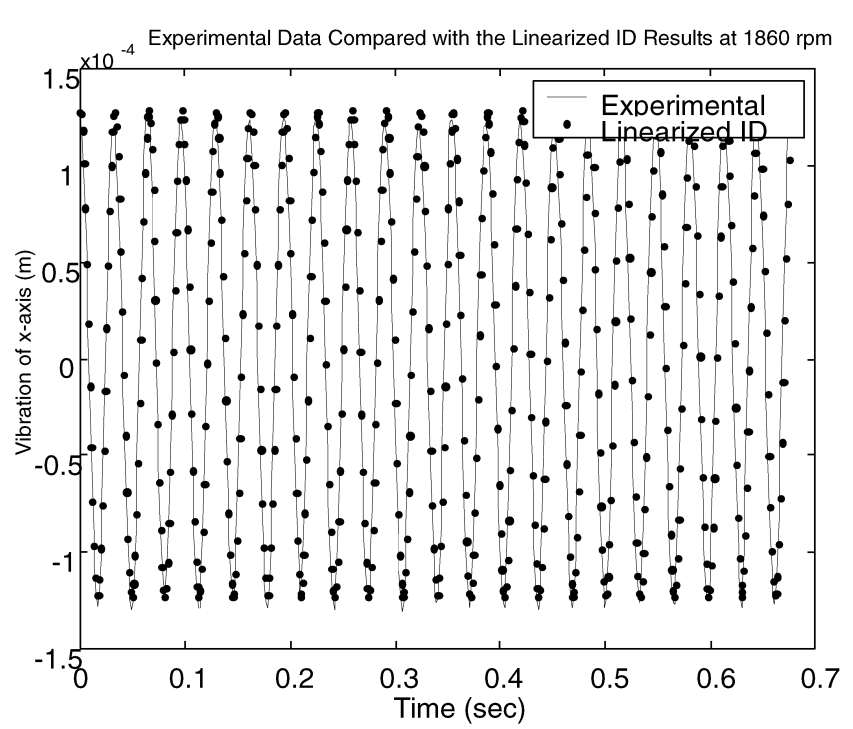

Fig. 5. Experimental data compared with the linearized ID results at $1860 \mathrm{rpm}$.

Table 3 shows the results by of system identification from $1400 \mathrm{rpm}$ to $1880 \mathrm{rpm}$. We also see that the damping coefficients are going to become small when the frequency gets large. It is noted that since the value of $\alpha$ is very small compared to that of $\beta$, so $\alpha$ is neglected. Figures 8 and 9 show the time responses experimental data, at $1860 \mathrm{rpm}$ and $1880 \mathrm{rpm}$ along the $x$-axis compared with the identification results for the oil film bearing system along the $x$-axis. To analyze the stability of the results in a nonlinear system, we need to calculate the eigenvalues of the Poincaré map. Because these cannot be computed directly in a nonlinear system model, we apply the method presented by Friedmann $e t$ al.[20]. The improved integration scheme for evaluating the transition matrix $\left[\Phi_{A}(T, 0)\right]$ is based upon the fourth order Runge-Kutta scheme with Gill coefficients. The most straightforward method for dealing with the stability of a periodic system consists of applying the

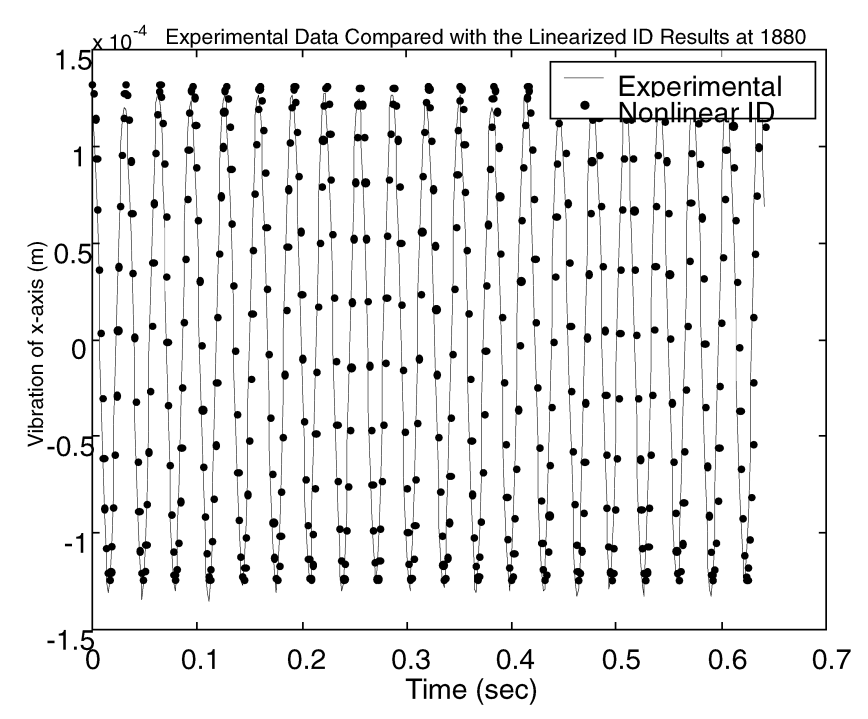

Fig. 6. Experimental data compared with the linearized ID results at $1880 \mathrm{rpm}$.

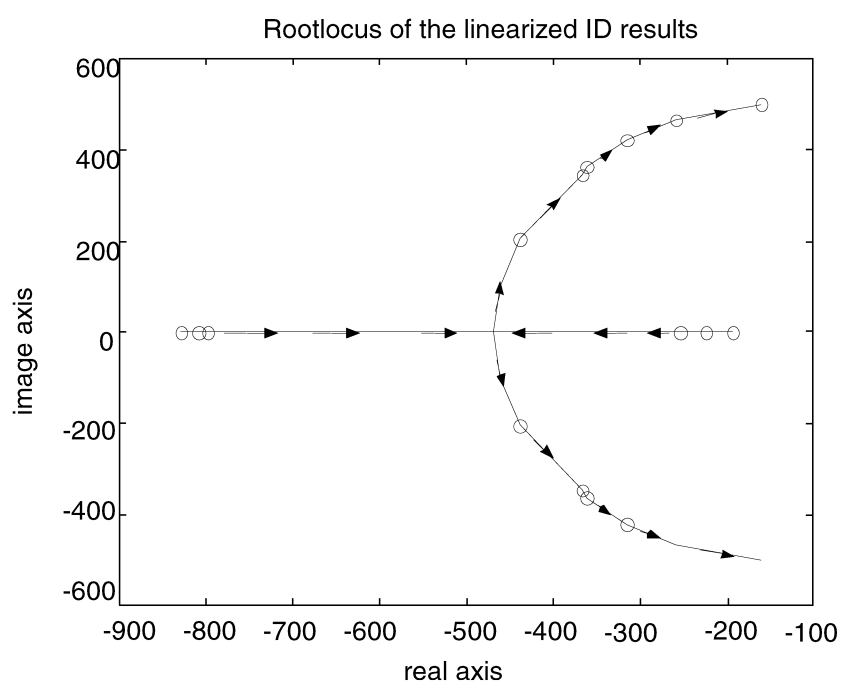

Fig. 7. Root locus of the linearized system. 
Table 3. ID results for a nonlinear system on the $x$-axis

\begin{tabular}{ccccc}
\hline Frequency $(\mathrm{rpm})$ & $m_{x}(\mathrm{Kg})$ & $c_{x}(\mathrm{Kg} / \mathrm{sec})$ & $k_{x}\left(\mathrm{Kg} / \mathrm{sec}^{2}\right)$ & $\beta$ \\
\hline 1400 & 0.0693 & 98.777 & 19135.400 & $-169.970 * 10^{10}$ \\
1500 & 0.0642 & 74.823 & 14523.634 & $-32.822^{*} 10^{10}$ \\
1600 & 0.0655 & 77.882 & 16682.132 & $-39.049^{*} 10^{10}$ \\
1700 & 0.0613 & 64.212 & 18621.703 & $-28.6371 * 10^{10}$ \\
1800 & 0.0586 & 48.344 & 17597.422 & $-12.728^{*} 10^{10}$ \\
1820 & 0.0525 & 45.370 & 17173.198 & $-9.926^{*} 10^{10}$ \\
1840 & 0.0508 & 37.433 & 16734.656 & $-5.528^{*} 10^{10}$ \\
1860 & 0.0529 & 31.762 & 17707.601 & $-4.656^{*} 10^{10}$ \\
1880 & 0.0550 & 21.277 & 18710.396 & $-6.083^{*} 10^{10}$ \\
\hline
\end{tabular}

Table 4. Eigenvalues of the transition matrix $\left[\Phi_{A}(T, 0)\right]$ in a nonlinear system

\begin{tabular}{cc}
\hline Frequency $(\mathrm{rpm})$ & Eigenvalues \\
\hline 1400 & $7.313^{*} 10^{-3}, 1.952^{*} 10^{-18}$ \\
1500 & $8.262 * 10^{-4}, 7.617^{*} 10^{-18}$ \\
1600 & $6.233 * 10^{-4}, 6.847 * 10^{-17}$ \\
1700 & $4.483 * 10^{-7}, 1.078^{*} 10^{-9}$ \\
1800 & $-1.030^{*} 10^{-6} \pm 1.906^{*} 10^{-7} \mathrm{j}$ \\
1820 & $-4.697 * 10^{-7} \pm 4.468^{*} 10^{-7} \mathrm{j}$ \\
1840 & $-3.442^{*} 10^{-6} \pm 4.925^{*} 10^{-6} \mathrm{j}$ \\
1860 & $-5.454 * 10^{-5} \pm 2.836^{*} 10^{-5} \mathrm{j}$ \\
1880 & $-1.049^{*} 10^{-3} \pm 1.755^{*} 10^{-3} \mathrm{j}$ \\
\hline
\end{tabular}

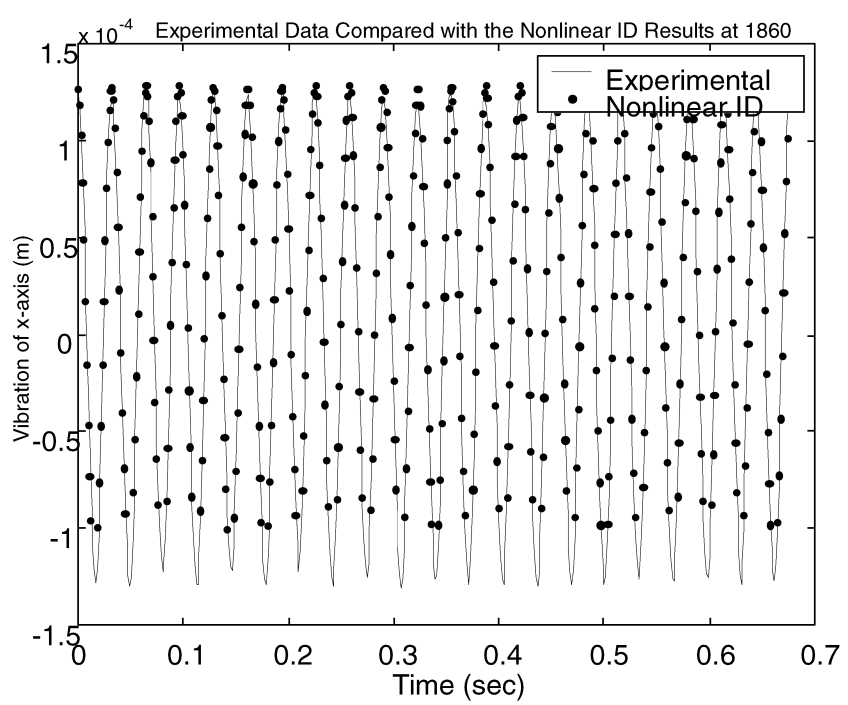

Fig. 8. Experimental data compared with the nonlinear ID results at 1860rpm.

Floquet-Liapunov theorem, that states that the knowledge of the state transition matrix over one period is sufficient in order to determine the stability of a periodic system. Thus, the approximate transition matrix at

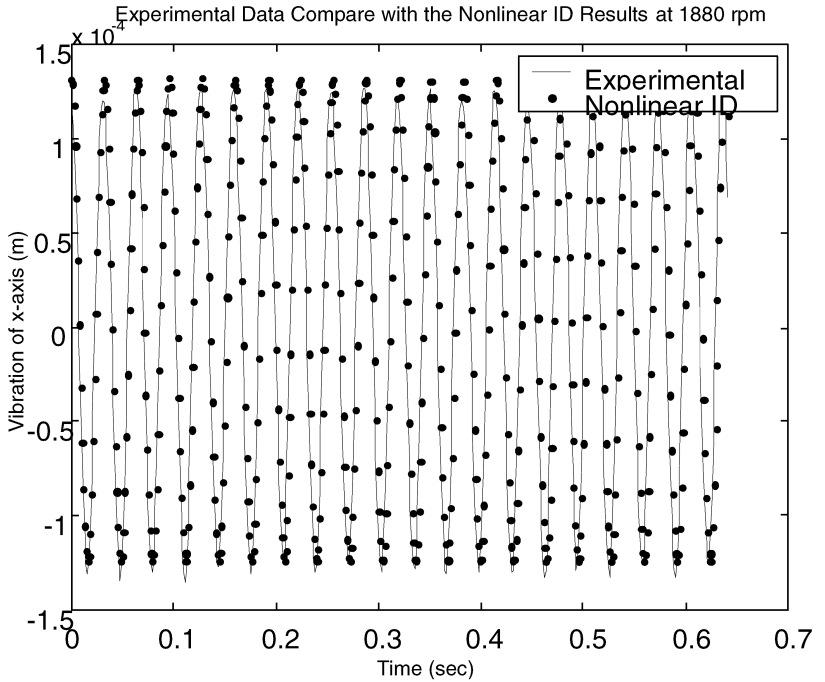

Fig. 9. Experimental data compared with the nonlinear ID results at 1880rpm.

the end of a period can be obtained by one integration pass. Table 4 shows the eigenvalues of the transition matrix $\left[\Phi_{A}(T, 0)\right]$ for our experimental system.

In Table 4, we see that all the eigenvalues are not outside the unit circle, but the complex eigenvalues change very fast between $1800 \mathrm{rpm}$ to $1880 \mathrm{rpm}$. From $1860 \mathrm{rpm}$ to $1880 \mathrm{rpm}$ they even differ by 2 orders. We expect that when the frequency is $1900 \mathrm{rpm}$, the eigenvalues may be over the unit circle. Comparing the results in Table 3 and Table 4, we can see that the tendency of the eigenvalues in both the linearized and the nonlinear models is similar. Figures 10, 11 and 12 show the root locus of the nonlinear system results on different scales. According to the bifurcation theory, if a pair of complex conjugate eigenvalue for a nonlinear system pass through the unit circle, then a Hopf bifurcation occurs, and a new vibrational structure appears. This actually predicts the occurrence and the behavior of the oil whirl. 


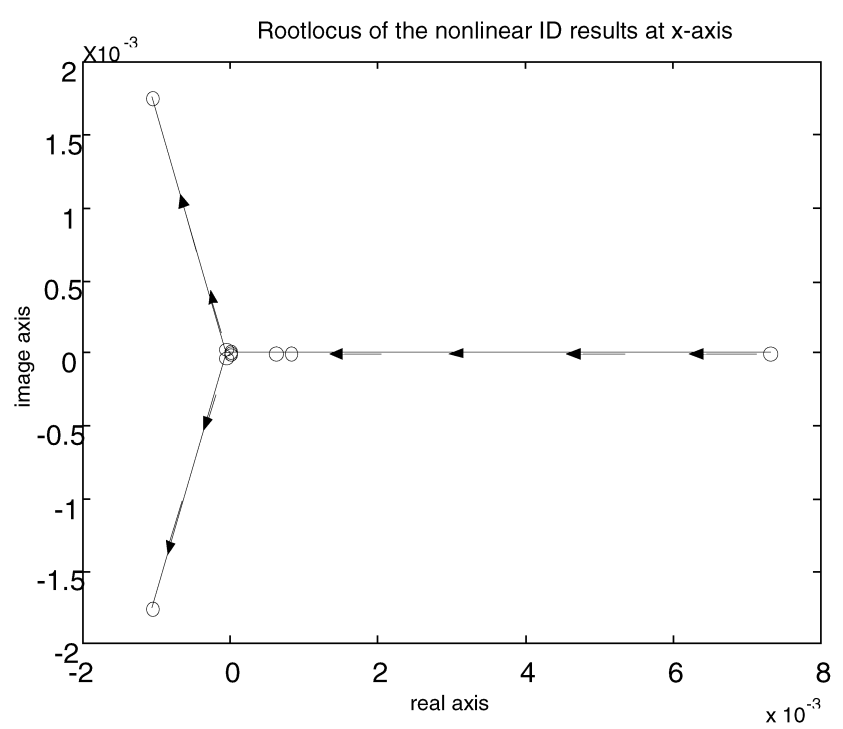

Fig. 10. Root locus of the nonlinear system.

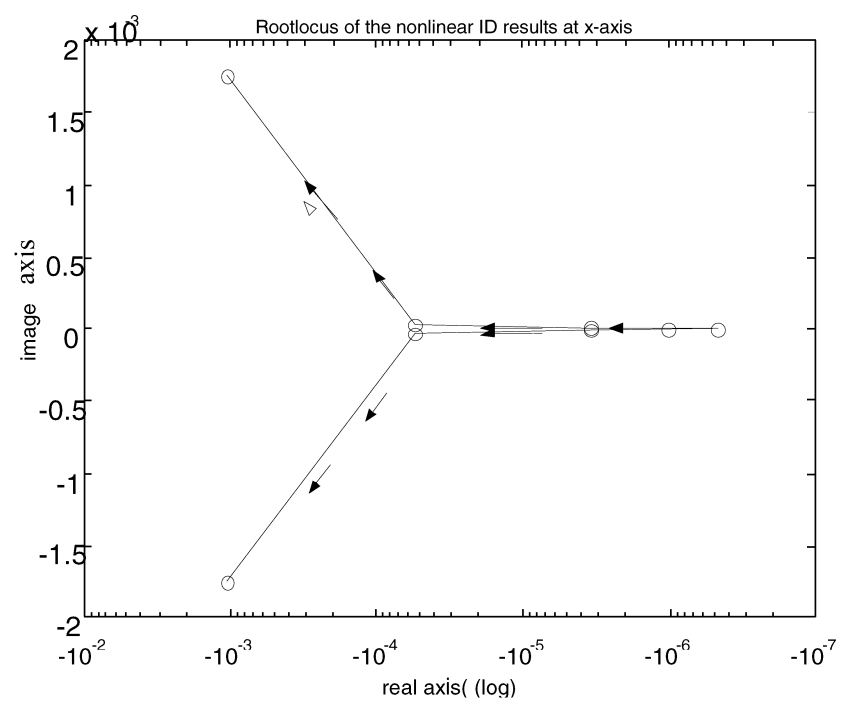

Fig. 11. Complex part of the eigenvalues using a logarithmic scale for a nonlinear system.

\section{CONCLUSION}

In practical applications, it is difficult to apply a persistent excitation for identification of an oil film system. In this paper we adapted an unbalanced force to excite the oil film system, and then developed a method to calculate the phase angle between the unbalanced force and the measured responses. Stability analysis and system performance are evaluated by the using root locus and Floquet-Liapunov theorem. Based on the identified model, the oil whirl in the journal bearing can be predicted. A comparison between the simulation

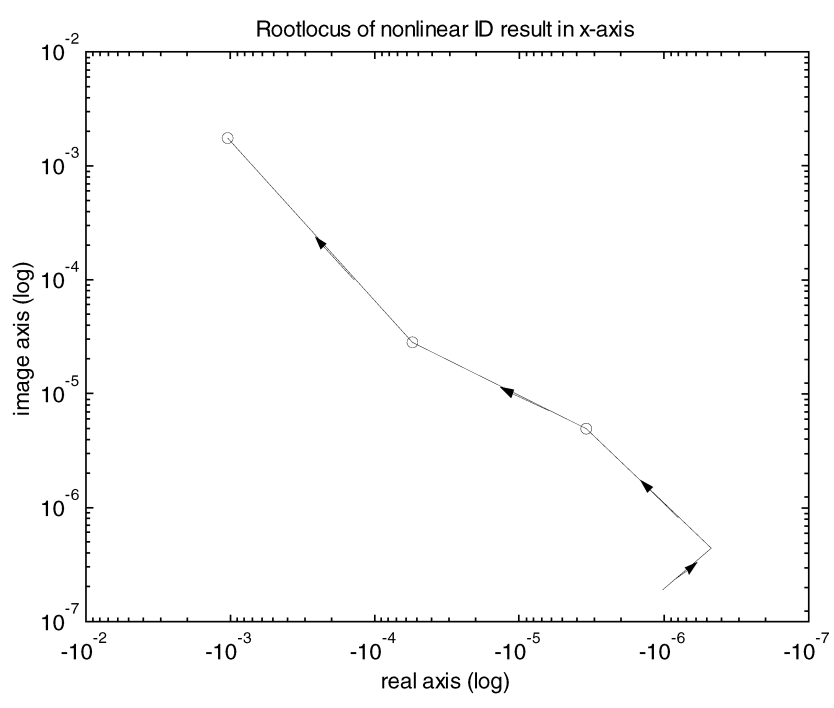

Fig. 12. Complex part of the eigenvalues using logarithmic scales for a nonlinear system.

results and the experimented data show the feasibility of the proposed approach.

\section{ACKNOWLEDGEMENT}

The authors would like to thank Jo-Wan Lin for this invaluable assistance and cooperation. The authors would also like to thank the support by National Science Council, Republic of China, through supporting this research under Grant No. NSC 88-TPC-E-008-001.

\section{REFERENCES}

1. Burrows, C.R., Sahinkaya , M.N. and Kucuk, N.C., "Modeling of Oil-Film Forces in Squeeze-Film Bearings," Transactions of the ASME, Journal of Tribokogy, Vol. 108, April, pp. 262-269(1986).

2. Dogan, I.U., Burdess, J.S. and Hewet, J.R., "Identification of Journal Bearing Coefficients Using a PseudoRandom Binary Sequence”, Institution of Mechanical Engineers Proceeding, Vol. 292, pp. 277-281(1980).

3. Glienicke, J., "Experimental investigation of the stiffness and Damping Coefficients of Turbine Bearings and their Application to Instability Prediction", Journal Bearing for Reciprocating and Turbomachinery, IME symposium, Nottingham, pp. 122-135(1966).

4. Muszynska, A., "Whirl and Whip-Rotor and Bearing Stability Problems", Journal of Sound and Vibration, Vol. 110, No. 3, pp. 443-462(1986).

5. Muszynska, A., Bently, D. E., Franklin, W. D., Grant, J. and Goldman, P., “Applications of Sweep Frequency Rotating Force Perturbation Methodolory in Rotating Machinery for Dynamic Stiffness Identification", Trans- 
action of the ASME, Vol. 115, pp. 266-271 (1993).

6. Morton, P.G., "Dynamic Characteristics of Bearing Measurement under Operating Condition", GEC Science \& Technology, Vol. 42, No. 1, pp. 37-47 (1975).

7. Nordmann, R. and Massmann H., "Identification of Dynamic Coefficients of Annular Turbulent Seals", Rotodynamic Instability Problems in High-Performance Turbomachinery, NASA CP 2338, College Station, TX, pp. 295-311 (1984).

8. Szabelski, K. and Warminski, J., "Parametric Self-Excited Non-linear System Vibrations Analysis with Inertial Excitation.", Int. J. Non-Linear Mechanics, Vol. 30, No. 2, pp. 179-189 (1995).

9. Someya, T., "An Investigation into the Spring and damping coefficient of the Oil Film in the Journal Bearing", Transaction of the Japan Society of Mechanical Engineers, Vol. 42, No. 360, pp. 2599-2606 (1976).

10. Zhang, Y.Y., Xie, Y.B. and Qiu, D. M., "Identification of Linear Oil-Film Coefficient in a Flexible Rotor-Bearing System, Part II: Experiment", Journal of Sound and Vibration, Vol. 152, No. 3, pp. 549-559 (1992).

11. Zhang, Y.Y., Xie, Y.B. and Qiu, D.M., "Identification of Linear Oil-Film Coefficient in a Flexible Rotor-Bearing System, Part I: Model and Simulation", Journal of Sound and Vibration, Vol. 152, No. 3, pp. 531-547 (1992).

12. Nordmann, R. and Schollhorn, K., "Identification of Stiffness and Damping Coefficients of Journal Bearing by Means of the Impact Method", Institution of Mechanical Engineers Proceeding, Vol. 285, pp. 231-238 (1980).

13. Rice, H.J., "Elimination of Truncation Error in the Identification of Vibrating Systems", Journal of Sound and Vibration, Vol. 155, No. 1, pp. 85-94 (1992).

14. Rice, H.J. and Fitzpatrick, J.A., "The Measurement of
Nonlinear Damping in Single-Degree-of Freedom Systems", Transaction of the ASME, Journal of Vibration and Acoustics, Vol. 113, January pp. 132-140 (1991).

15. Roemer, M. J. and Mook, D.J., "Mass, Stiffness, and Damping Matrix Identification: An Integrated Approach", Transactions of the ASME, Journal of Vibration and Acoustics, Vol. 114, July, pp. 358-363 (1992).

16. Zhao, Y., Linnett I.W. and Mclean L.J., "Subharmonic And Quasi-Periodic Motions of an Eccentric Squeeze Film Damper-Mounted Rigid Rotor", Journal of Vibration and Acoustics, July, Vol. 115, pp. 357-363 (1994).

17. Steffen, V., Jr. and Rade, D.A., "An Identification Method of Multi-degree-of-Freedom System Based on Fourier Series", The International Journal of Analytical and Experimental Modal Analysis, Vol. 6, No. 4, Oct., pp. 271-278 (1991).

18. Yasda, K., Kawamura, S. and Watanbe, K., "Identification of Nonlinear Multi-Degree-of Freedom Systems (Presentation of an Identification Technique)", JSME International Journal: Series III, Vol. 31, No. 1, pp. 8-14 (1988).

19. Yau, H.T., Chen, C.K. and Chen, C.L., "Chaos and Bifurcation-Analysis of a Flexible Rotor Supported by Short Journal Bearings with Nonlinear Suspension” Proceedings of the Institution of Mechanical Engineers Part C-Journal of Mechanical Engineering Science, Vol. 214, Iss. 7, pp. 931-947 (2000).

20. Friendmann, P., Hammond, C. E. and Woo, T.H., "Efficient Numerical Treatment of Periodic Systems with Application to Stability Problem", International Journal for Numerical Method in Engineering, Vol. 11, pp. 1117-1136 (1977).

21. Söderström, T. and Stoica, P., System Identification, Prentice Hall, New York (1989). 